\title{
MÚLTIPLAS POSSIBILIDADES DE TRABALHO NAS AULAS DE CIÊNCIAS POR MEIO DA HORTA ESCOLAR
}

\section{MULTIPLE POSSIBILITIES OF WORK IN THE LESSONS OF SCIENCES BY MEANS OF THE VEGETABLE GARDEN}

\author{
Leandro Henrique Wesolowski Tavares ${ }^{1}$, James Rogado ${ }^{2}$ \\ ${ }^{1}$ Universidade Estadual Paulista, 1htavare@yahoo.com.br \\ ${ }^{2}$ Universidade Metodista de Piracicaba, jrogado@unimep.br
}

\section{Resumo}

Os Parâmetros Curriculares Nacionais (PCN) oferecem algumas possibilidades de trabalho na linha de alimentos/alimentação, aparecendo temas como utilização dos recursos disponíveis de forma equilibrada, plantio de hortas e árvores frutíferas, entre outros. Nesse sentido, buscamos conhecer as possibilidades/contribuições do trabalho com a horta nas aulas de Ciências. A pesquisa foi realizada a partir da parceria firmada entre os Cursos de Química-Licenciatura (UNIMEP) e Ciências Biológicas (ESALQ/USP) e uma Escola Estadual do município de Piracicaba-SP, envolvendo a participação de estudantes universitários, formadores de professores, equipe diretiva/pedagógica, professores do Ensino Fundamental e funcionários da unidade escolar na realização de atividades relacionadas à horta com quintas e sextas séries do Ensino Fundamental. O levantamento de dados seguiu as orientações de Lüdke e André (1986) referentes à observação participante. Pudemos perceber contribuições significativas na parceria Universidade-Escola, promovendo atividades que contemplam o caráter conceitual, atitudinal e procedimental.

Palavras-chave: Ensino de Ciências, Horta.

\begin{abstract}
The Brazilian's National Documents of Education (PCN) offer possibilities of work on food/alimentation, appearing subjects as use of the available resources of equilibrate form, plantation of vegetable garden and fruitful trees, among others. In this direction, we search to know the possibilities/contributions of the work with vegetable garden in the lessons of Sciences. This research was made through from a firmed partnership between Courses of Chemistry (UNIMEP) and Biological Sciences (ESALQ/USP) and a Basic School from Piracicaba-SP (Brazil), involving the participation of university, university teachers, Team Directive/Pedagogical, teachers of Basic Education and employee in the accomplishment of activities related to vegetable garden with fifth and sixth series of Basic Education. The collect of data followed the orientations of Lüdke and André (1986). We perceive significant contributions in the partnership UniversitySchool, promoting activities that contemplate the conceptual, attitudinal and procedural character.
\end{abstract}

Key words: Science Education, Vegetable garden 


\section{Introdução}

Existem cada vez mais pesquisas mostrando o quadro preocupante da saúde alimentar da população, destacando-se a situação da saúde das crianças. O documento escrito pela Organização Mundial de Saúde (OMS), denominado Projeto de Estratégia Mundial sobre Regime Alimentar, Atividade Física e Saúde, revela o aumento de enfermidades causadas pela ingestão inadequada de alimentos, resultando em problemas cardiovasculares, diabete tipo 2, alguns tipos de câncer, além de cáries e osteoporose. Dessa forma, as propostas de intervenção para reverter essa situação são essenciais frente a esse cenário. (NETO; PEREIRA, 2005).

A escola pode ser um dos caminhos para a construção de programas de saúde, principalmente por ser um local privilegiado que atende crianças e adolescentes de várias faixas etárias. Os Parâmetros Curriculares Nacionais oferecem algumas propostas de trabalho na linha de alimentos/alimentação. A parte relacionada à nutrição aparece nas Ciências Naturais da $1^{\mathrm{a}}$ a $4^{\mathrm{a}}$ séries, principalmente no bloco Saúde/Recursos Tecnológicos: possibilidade de trabalhar com a natureza e os recursos disponíveis de forma equilibrada; plantio de hortas e árvores frutíferas; estudo dos peixes e dos temas relacionados à comunidade local. (NETO; PEREIRA, 2005).

Kaufman e Serafini (1998) reforçam as propostas existentes para o trabalho no Ensino Fundamental, apresentando temas como o solo, o ar, solo-animal, microorganismos no solo, fotossíntese, entre outros. Assim, propõem que a construção da horta na escola pode possibilitar o estudo da dinâmica de fenômenos naturais, bem como o estudo das relações estabelecidas entre os elementos componentes da horta.

Somando-se a essas questões, acreditamos que a intervenção nas escolas, por meio da horta escolar, remete para questões ligadas à educação ambiental, enfoque de ensino que vem recebendo ênfase por parte de diversos pesquisadores. (REIGOTA, 2001; MIRANDA; KLEIN; MUCCIATO, 2005). Esse enquadramento da horta no contexto da educação ambiental se justifica, e se fortifica, devido à relação homem/natureza. (MIRANDA; KLEIN; MUCCIATO, 2005).

Nesse contexto, como lembram Chapani e Daibem (2001), a temática ambiental começou a receber destaque e proporcionar a reformulação dos objetivos educacionais em razão das preocupações geradas com a degradação ambiental e, conseqüentemente, a escassez de recursos naturais. 
Resultado do progresso e desenvolvimento atingidos pela humanidade, a educação ambiental surge com o papel de possibilitar a preservação e restauração do meio que foi bruscamente alterado pela atividade modernizadora do homem. (MELLO, 1996 apud MIRANDA; KLEIN; MUCCIATO, 2005).

Para reverter esse quadro, segundo Reigota (2001), a população deve ter claro que o problema ambiental é resultado do excessivo consumo dos recursos naturais, sendo grande parte desses recursos consumidos por uma pequena parcela dos seres humanos, além dos desperdícios gerados e a produção de artigos inúteis. Nesse panorama, a educação ambiental deve resultar numa educação política, possibilitando a preparação de cidadãos mais conscientes que reivindiquem justiça social, cidadania nacional e planetária, e respeito nas relações sociais e com a natureza para gerar um crescimento econômico de modo a minimizar (ou se possível eliminar) as repercussões nocivas do sistema econômico.

Dessa forma, a horta escolar pode ser um dos meios que proporcionem a mudança de valores, atitudes e hábitos dos alunos, professores e, dependendo da amplitude da proposta de trabalho, da própria comunidade em relação ao ambiente. A partir desse contato aluno-horta, podemos engajar a criança no processo de plantar e cultivar alimentos com vista à sobrevivência alimentar e disponibilizar aprendizados no que se refere ao uso benéfico da terra - agora e no futuro. (NUTTAL, 1996 apud MIRANDA; KLEIN; MUCCIATO, 2005).

A importância levantada e discutida sobre questões de cidadania, solidariedade, valores, são fundamentais durante a formação escolar dos alunos e podem ser relacionadas ao fator atitudinal destacado nos Parâmetros Curriculares Nacionais. Contudo, entendemos que o trabalho com a horta escolar pode expandir essa visão, chegando à questão conceitual mencionada nos Documentos Oficiais.

Reigota (2001) lembra que a comunidade internacional incentiva o aparecimento da educação ambiental nos mais variados espaços que educam os cidadãos: parques e reservas ecológicos; associações de bairro; sindicatos; universidades; meios de comunicação de massa etc. Somando-se a essa questão, a Lei n ${ }^{\circ} 9.785$ de 17 de abril de 1999, relata que a educação ambiental deva estar permeando os variados níveis e modalidades do ensino formal. Acreditamos que a educação ambiental deve permear os conhecimentos e conceitos das disciplinas que compõem o currículo escolar, não sendo necessário a criação de uma disciplina específica para acoplá-la. 
Nessa perspectiva, a educação ambiental pode permitir o trabalho escolar a partir de problemas locais já estabelecidos na comunidade, possibilitando empregar os conhecimentos científicos conhecidos na resolução desses problemas ambientais. (REIGOTA, 2001).

Sob outro viés, o tema Horta propõe o trabalho em um ambiente que é diretamente influenciado por problemas ligados à natureza, como a utilização de agrotóxicos, pesticidas, fungicidas, os quais podem contaminar os alimentos produzidos pela horta e o solo ao seu redor. Em certos casos pode existir até a contaminação de lençóis freáticos nas proximidades da área de cultivo.

Somando a essa questão, podemos acrescentar a questão do lixo gerado (resíduos urbanos) pela comunidade, o qual é depositado em lixões e aterros, sendo um problema, principalmente o lixo de origem orgânica que forma o chorume, subproduto líquido de coloração escura que contamina os solos e os corpos de água. (DOMINGUES; TOMÁS; FEHR, 2004).

Uma ação possível para minimizar esses efeitos é a prática de compostagem, processo pelo qual acontece a decomposição biológica da matéria orgânica - resíduos animais ou vegetais -, por meio de microorganismos e animais invertebrados em presença de umidade e oxigênio, fazendo com que os elementos químicos dessa matéria orgânica voltem ao solo na forma de nutrientes. (SILVA; CHITOLINA; BALLESTERO; VOIGTEL; MELO, 2005; INFORMATIVO RECICLOTECA, 2007).

A partir dessas considerações, buscamos conhecer as possibilidades e as contribuições do trabalho com a horta escolar nas aulas de Ciências do Ensino Fundamental.

\section{Desenvolvimento}

Para a concretização dessa investigação, realizamos uma parceria UniversidadeEscola durante o primeiro e segundo semestres de 2007. Nesse sentido, os passos iniciais foram destinados à criação da parceria, por meio de conversas e reuniões entre os graduandos dos Cursos de Química-Licenciatura e Ciências Biológicas (UNIMEP e ESALQ/USP, respectivamente) e a Equipe Diretiva e Pedagógica de uma Escola Pública. As três instituições de ensino estão localizadas na cidade de Piracicaba, interior do Estado de São Paulo. 
Nos primeiros encontros entre os participantes foi acertado que as atividades de ensino referentes à horta seriam realizadas em três classes do Ensino Fundamental, sendo uma $5^{\mathrm{a}}$ série e duas $6^{\mathrm{a}}$ séries. Nesse sentido, em reunião agendada, os graduandos listaram algumas possibilidades de atividades a serem desenvolvidas, juntamente com os professores, nas disciplinas de Matemática, Ciências, Informática, História, uma vez que eram essas as disciplinas ministradas pelos professores interessados no projeto horta. Na mesma reunião, ainda houve a troca de e-mails para facilitar a comunicação entre os participantes, possibilitando o envio de propostas de atividades e/ou outras informações.

No início do diálogo e estruturação da pesquisa, escolhemos a observação participante, descrita por Lüdke e André (1986), como modalidade de campo, uma vez que reúne aspectos como a análise documental, a observação e a participação dos pesquisadores nas atividades. Dentro dessa perspectiva de pesquisa, realizamos a coleta de dados a partir de estratégias como a observação das atividades e anotações em caderno de campo.

Das propostas de atividades às suas execuções foram necessárias leituras variadas sobre o tema horta, buscando uma revisão bibliográfica sobre a temática. Assim, realizamos as leituras de textos, artigos e livros relacionados à compostagem, a atividade microbiana, ao solo, ao plantio de mudas e preparação de canteiros na horta.

Nos meses iniciais, a coordenadora pedagógica da escola contatou a prefeitura de Piracicaba (SP) para expor a realização desse projeto, visando captar recursos para a construção da Horta e à realização de atividades pedagógicas com a mesma. Nesse cenário, conseguimos apoio da prefeitura, como a disponibilização de um trator para a limpeza da área destinada à construção dos canteiros da horta (foto 1). 


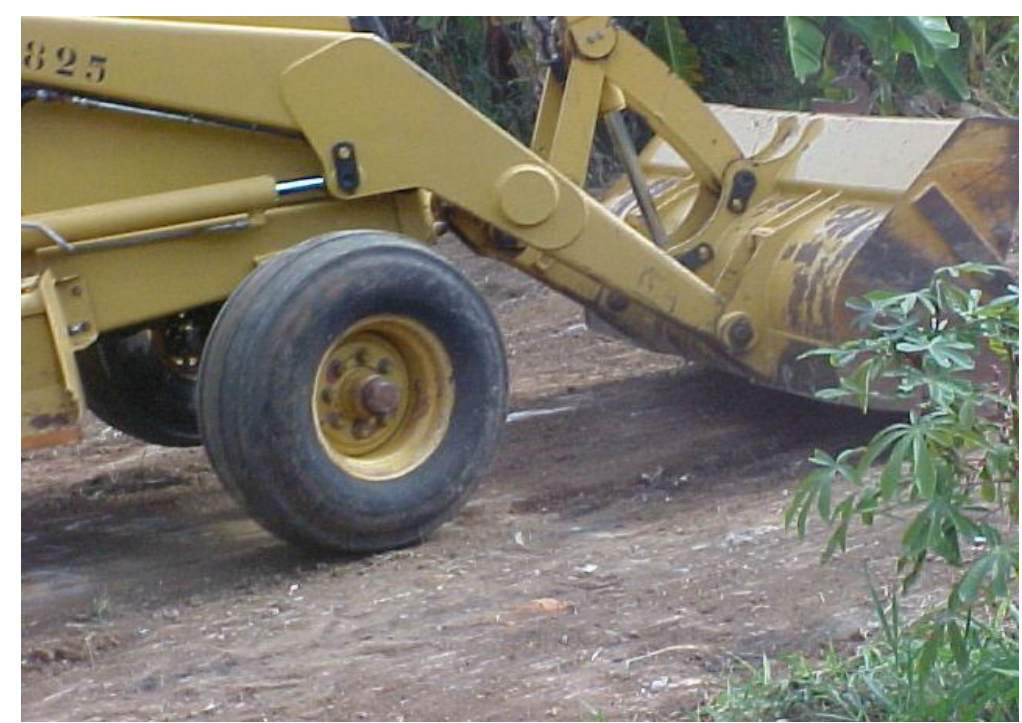

Foto 1 - Trator limpando o local da horta

A prefeitura também forneceu ferramentas e equipamentos necessários à construção e manutenção dos canteiros, envolvendo a compra de mangueira, luva, pá, enxadas, martelo, rastelo, carrinho de mão, regador e alguns metros de tela de ferro para cercar a área. A foto 2 apresenta a preparação e nivelamento do local destinado à construção da horta a partir de alguns caminhões de terra doados pela prefeitura.

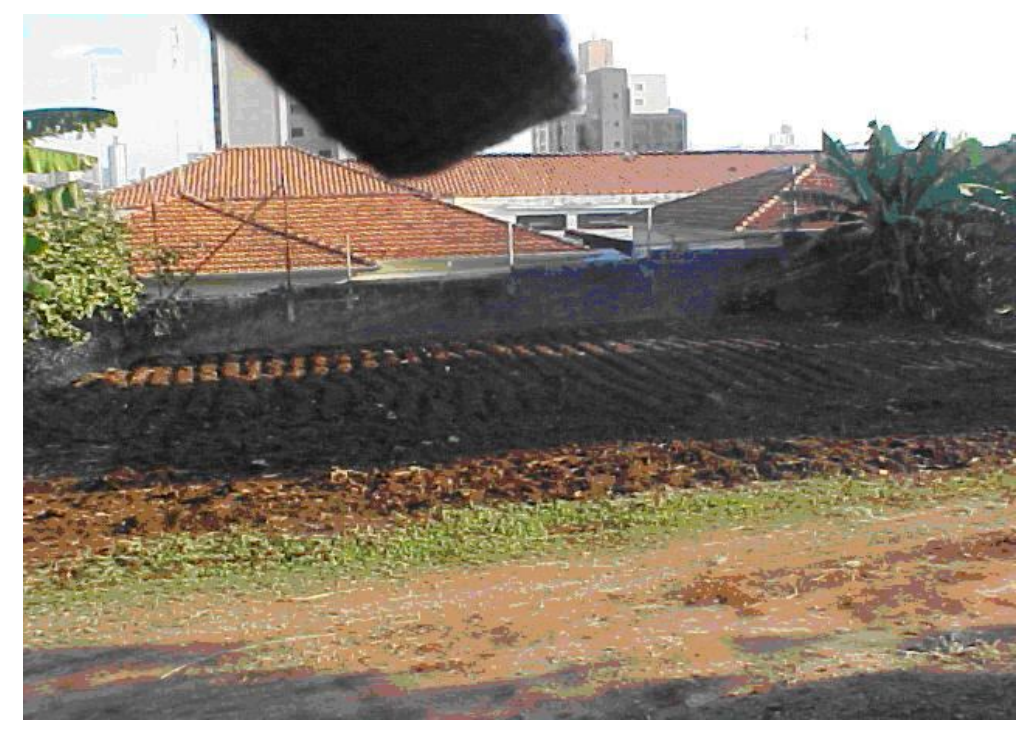

Foto 2 - Nivelamento para a construção dos canteiros

A primeira atividade desenvolvida, após a seleção das classes participantes da pesquisa, foi a fixação do painel horta (foto 3) na quinta e nas sextas séries. 
Realizamos, nesse dia, discussões sobre as regras a serem seguidas/respeitadas durante o trabalho com a horta, bem como mostramos que o painel serviria como orientador das nossas ações ao contar com o quadro de avisos, aspectos sobre a irrigação, as etapas de funcionamento da composteira e os grupos responsáveis por cada canteiro da horta. As cinco regras combinadas buscam criar normas de convivência entre os participantes, envolvendo aspectos como: respeito (na interação com a horta e entre os participantes); atenção nas ações (no desenvolvimento das atividades); participar com idéias (buscando gerar criatividade e interação nas tarefas); esclarecimento das dúvidas (possibilitando maior aprendizagem e participação nas atividades realizadas); rapidez nas ações (visando otimizar tempo nas descidas ao local da horta e nas subidas às salas de aula).

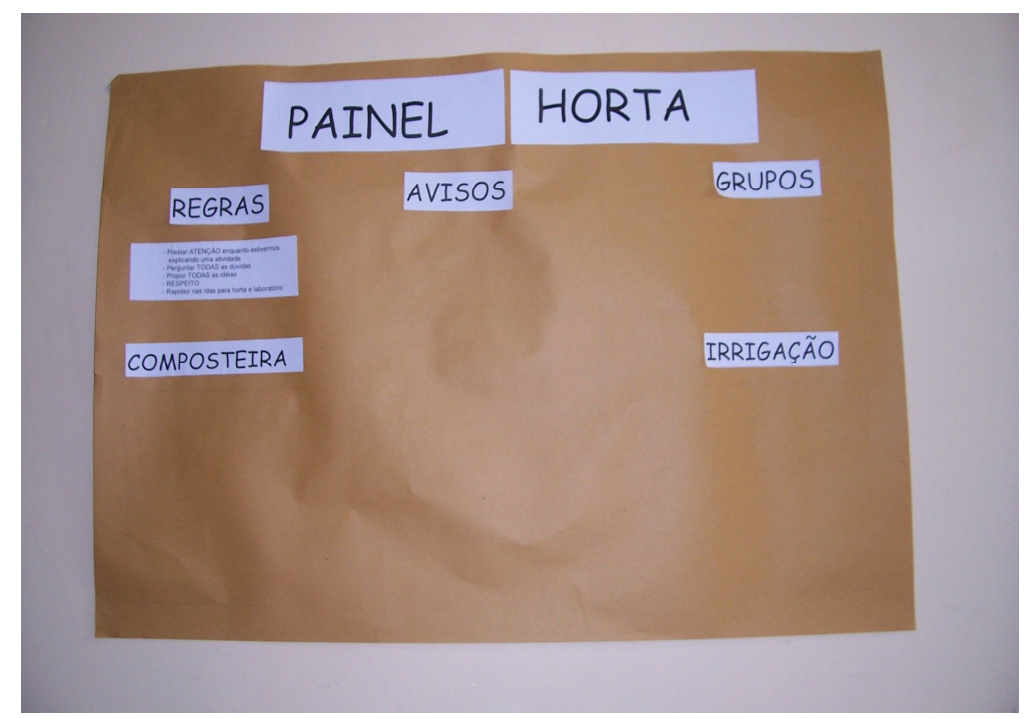

Foto 3 - Painel horta fixado pelos alunos

Pudemos estabelecer, nos primeiros encontros com os alunos, relações de parceria e apoio mútuo na efetivação das atividades. Nesse sentido, negociamos a divisão dos alunos em grupos que ficaram responsáveis pelos canteiros da Horta. Com 36 alunos, criamos quatro grupos na quinta série, cada um responsável por um canteiro (Canteiro 1 - beterrabinha; Canteiro 2 - ruculazinha; Canteiro 3 - pimentinha; Canteiro 4 - alface). Dividimos a sexta série A em dois grupos (11 e 12 alunos), seguindo a mesma estrutura (Canteiro 5 - batatinha; Canteiro 6 - tomatinho). A sexta série B também seguiu essa estrutura, contando com dois grupos de 12 alunos responsáveis pelos dois últimos canteiros da horta (Canteiro 7 - cenourinha; Canteiro 8 - cebolinha). A quinta 
série foi dividida em mais grupos devido a quantidade de alunos que comporta, sendo importante destacar que foram os alunos de cada grupo que nomearam o seu canteiro.

Entre as primeiras atividades desenvolvidas com os alunos, destacamos as discussões geradas com os problemas dos lixões, englobando assuntos como os bichos, as epidemias e as doenças transmitidas nesses locais; a formação do chorume, um subproduto líquido que contamina os solos e os corpos de água; os 3 R's (reduzir, reutilizar, reciclar). Nessa linha, discutimos as experiências que esses alunos tiveram/presenciaram sobre a aplicação dos 3R's em diversos contextos, acabando por enquadrar a compostagem como uma atividade que realizaríamos para reciclar os nutrientes, ou seja, devolveríamos os nutrientes presentes nas cascas de frutas e legumes adquiridos, via cantina da escola, ao solo para serem utilizados pelas hortaliças do projeto Horta.

Explicamos, em sala de aula, as etapas sucessivas que a composteira deve passar para seu funcionamento adequado, ficando, a partir daquele momento, sob responsabilidade dos alunos a manutenção da mesma. Assim, depositaríamos o material orgânico a ser processado, sendo coberto por palha seca e regado para manter a umidade. A última etapa seria o revolvimento do monte compostado, facilitando a circulação do ar nas leiras.

Em seguida, descemos com os alunos para apresentar a composteira (foto 4), relatando que a transformação do material orgânico em adubo acontece pela atividade de microorganismos aeróbicos (bactérias e fungos que necessitam de oxigênio) sobre as cascas de frutas e legumes. Assim, deixamos claro que a formação do húmus seria prejudicada se dificultássemos a ação dos microorganismos, ou seja, discutimos que a formação de adubo é prejudicada se alguma variável (aeração, umidade, temperatura) da atividade microbiana é afetada. 


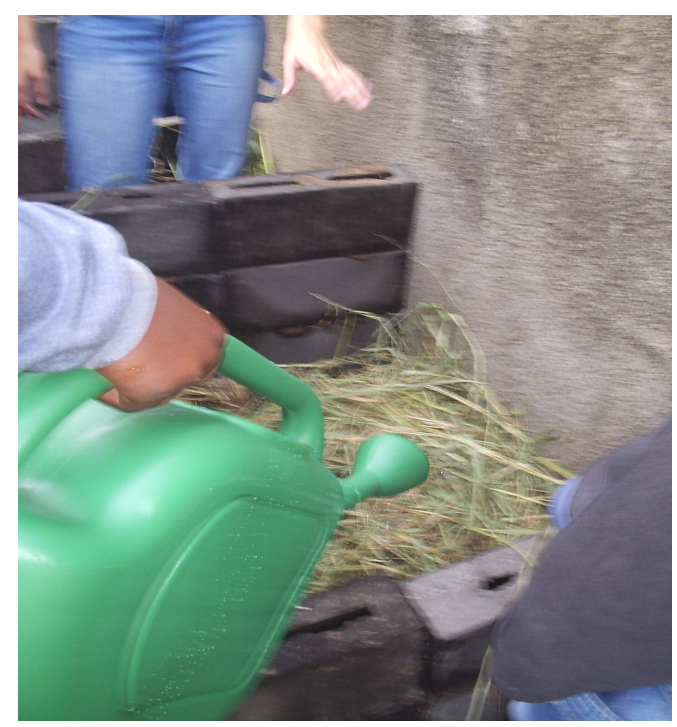

Foto 4 - Atividade com a composteira

Dessa forma, apresentamos como os alunos deveriam proceder para realizar o revolvimento do monte, deslocando o material orgânico a cada dois dias (segunda, quarta e sexta-feira) para promover a circulação do oxigênio. Explicamos que essa etapa tinha como função fornecer oxigênio para os microorganismos aeróbicos que trabalhavam sobre a matéria orgânica. Destacamos que o teor de água deveria ser moderado, pois muita água atrapalha a livre circulação de oxigênio, criando áreas anaeróbicas - responsáveis pelo mau odor. Enquanto que o emprego de pouca água resultaria na limitação da atividade dos microorganismos sobre a matéria orgânica.

Esclarecemos que a elevação da temperatura das leiras $\left(\cong 60^{\circ} \mathrm{C}\right)$ seria resultado da atividade microbiana, uma vez que os microorganismos aeróbicos desse processo possuem um metabolismo exotérmico, ou seja, um metabolismo que libera energia (na forma de calor) durante sua ação sobre os alimentos. Essa etapa foi importante para determinarmos, junto aos alunos, a quantidade aproximada de água para o bom funcionamento desse processo ( $\cong 55 \%$ de umidade).

Utilizamos essas discussões e atividades com a composteira como ponto de partida para trabalhar com um experimento sobre bactérias. Nesse sentido, pudemos levantar questões como o que são as bactérias e como elas podem ser vistas, enfatizando o papel desses microorganismos no funcionamento da composteira. Aproveitamos as possibilidades desse tema para realizar um experimento de crescimento de uma colônia de microorganismos das leiras a partir de um meio de cultura alternativo, construído com materiais de fácil obtenção (meio nutritivo gerado a partir da mistura de gelatinas e 
sulcos fervidos de batata e beterraba). Ao final, disponibilizamos um site com maiores informações sobre esse tema.

Para além do trabalho em sala de aula e na composteira, o tema horta também possibilitou a realização de uma excursão à exposição "solo na escola" que ocorria na ESALQ/USP - Piracicaba (SP), tendo como objetivo trabalhar vários experimentos sobre o solo com alunos das escolas de Ensino Fundamental.

A exposição contava com monitores que dividiam a classe em grupos de alunos para facilitar a apresentação dos experimentos, contando com temas como: processos erosivos do solo; absorção de água pelo solo (solo com cobertura vegetal; solo com folhas; e solo limpo - foto 5); tipos de solo existentes; permeabilidade do solo; formas de purificação da água; estágios de crescimento do milho em solos com características diferentes (comparação do crescimento vegetal em solo normal e solo com adubação foto 6); comparação da textura de diferentes solos.

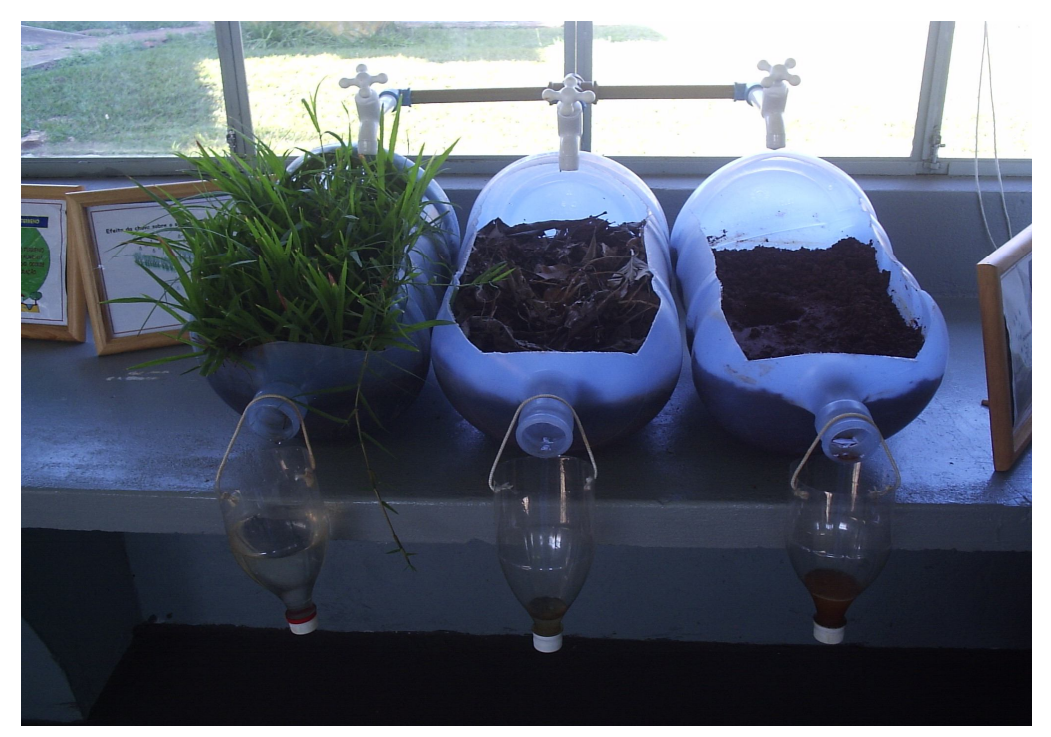

Foto 5 - Absorção da água pelo solo 


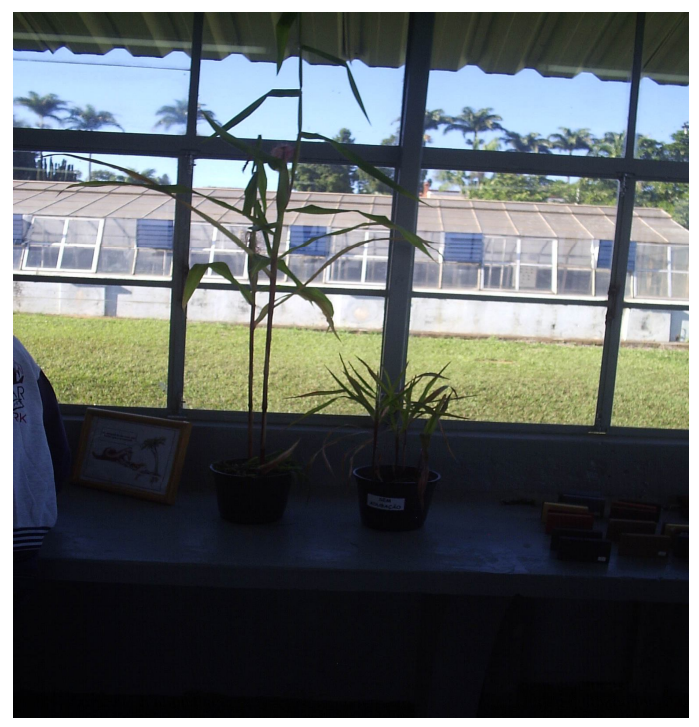

Foto 6 - Estágios de crescimento do milho em solo normal e com adubação

A última atividade que gostaríamos de destacar foi o plantio das primeiras hortaliças. Nessa atividade, pedimos para os alunos trazerem embalagens/potinhos de produtos usados em casa (potes de iogurte, molho de tomate, café, ou outros) para realizarmos o plantio indireto, sendo uma ação necessária para as sementes que ainda são muito frágeis e/ou novas. Assim, distribuímos 4 ou 5 sementes de hortaliças diversificadas para os alunos plantarem e regarem (pelo menos duas vezes por dia - de manhã e no fim da tarde) antes de serem transferidas para o canteiro.

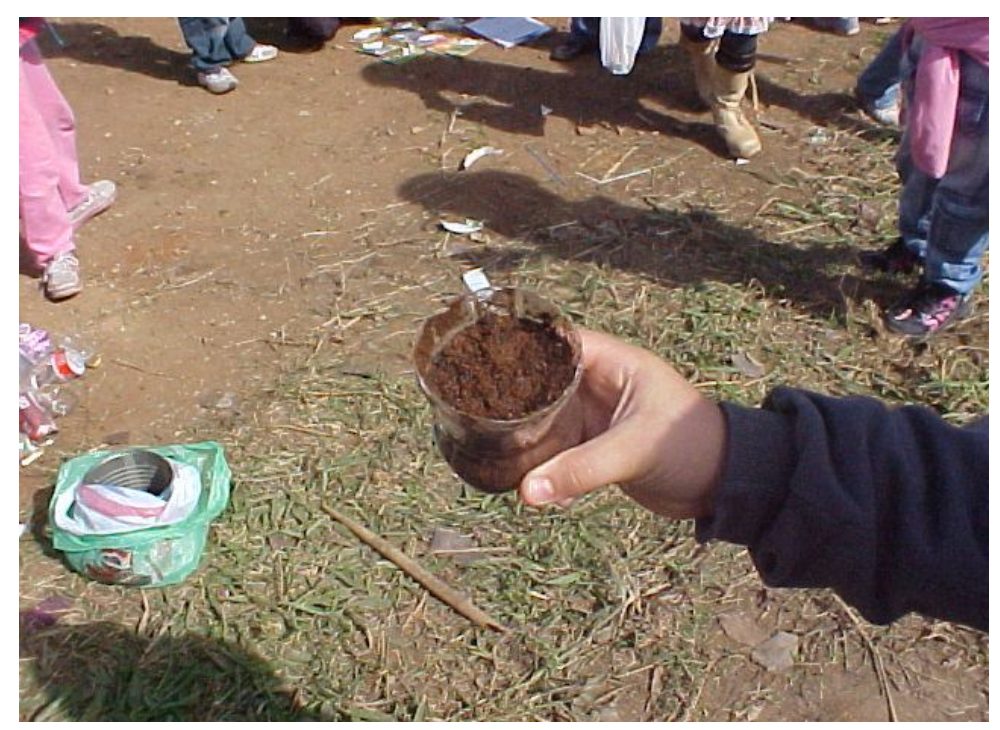

Foto 7 - Plantio indireto 
Essa atividade também possibilitou a discussão sobre o ato de reutilizar os objetos (3 R's), uma vez que reutilizamos os potinhos de tomate (entre outros tipos de embalagem) que seriam descartados no lixo.

\section{Considerações Finais}

$\mathrm{Na}$ análise das atividades realizadas com os alunos, pudemos perceber várias contribuições - como a articulação Universidade-Escola, fazendo com que licenciandos, professores, funcionários, coordenador pedagógico e equipe diretiva se unissem em pró de um bem comum: implantar e trabalhar em torno de atividades relacionadas à Horta. Assim, a partir da realização dessas atividades, presenciamos ricas possibilidades de trabalho, assim como as evidenciadas na pesquisa de Morgado (2006), em que a horta possibilita o trabalho teórico, a realização de atividades práticas e a interação entre os participantes.

\footnotetext{
A horta inserida no ambiente escolar pode ser um laboratório vivo que possibilita o desenvolvimento de diversas atividades pedagógicas em educação ambiental e alimentar unindo teoria e prática de forma contextualizada, auxiliando no processo de ensino-aprendizagem e estreitando relações através da promoção do trabalho coletivo e cooperado entre os agentes sociais envolvidos. (MORGADO, 2006, p. 1).
}

Nesse sentido, percebemos que o trabalho com a Horta vai ao encontro dos três pilares evidenciados pelos PCN do Ensino Fundamental, promovendo atividades que contemplem o caráter conceitual (ensino de conteúdos referentes à Horta/composteira/microorganismos), atitudinal (trabalho de conscientização sobre o lixo gerado/3 R's/interação entre os agentes envolvidos nas ações) e procedimental (construção e manutenção da composteira/técnicas de plantio).

\section{Referências Bibliográficas}

CHAPANI, D. T.; DAIBEM, A. M. L. Algumas Considerações sobre as Relações entre Meio Ambiente, a Espécie Humana, Cidadania e Escola: Implicações na Implementação de um Programa de Educação Ambiental. In: Atas do III Encontro Nacional de Pesquisa em Educação em Ciências, Atibaia-SP, 2001. 
DOMINGUES, M. M. O.; TOMÁS, L. R.; FEHR, M. O Aporte da Comunidade Escolar à Coleta Diferenciada de Resíduos Sólidos. In: IV Simpósio Internacional de Qualidade Ambiental. Porto Alegre, 2004.

Informativo Recicloteca. Compostagem: A Reciclagem na Natureza, n. 25, p. 4-5, abril-maio-junho de 2003.

KAUFMAN, M.; SERAFINI, C. A Horta: Um Sistema Ecológico. In: WEISSMANN, Hilda (org.). Didática das Ciências Naturais: contribuições e reflexões. Porto Alegre: ArtMed, 1998.

LÜDKE, M.; ANDRÉ, M. E. D. A. Pesquisa em Educação: Abordagens Qualitativas. São Paulo: Editora EPU, 1986.

MIRANDA, P. N.; KLEIN, T. A. S.; MUCCIATO, M. Horta Escolar: Uma Experiência de Educação Ambiental na Barra do Superagui, PR. In: Atas do V Encontro Nacional de Pesquisa em Educação em Ciências, Bauru-SP, 2005.

MORGADO, F. S. A horta escolar na educação ambiental e alimentar: experiência do Projeto Horta Viva nas escolas municipais de Florianópolis. Florianópolis (SC), 2006. (Monografia).

NETO, P. C. P.; PEREIRA, R. B. A Tabela de Composição de Alimentos na Educação Escolar. In: SALAY, E. (org.). Composição de Alimentos: uma abordagem multidisciplinar. Campinas: Núcleo de Estudos e Pesquisas em Alimentação, 2005.

REIGOTA, M. O que é Educação Ambiental. São Paulo: Brasiliense, 2001.

SILVA, F. C.; CHITOLINA, J. C.; BALLESTERO, S. D.; VOIGTEL, S. D. S.; MELO, J. R. B. Processos de produção de compostos de lixo e a sua qualidade como fertilizante orgânico. Revista HOLOS Environment, vol. 5, n. 2, p. 121-136, 2005. 